\section{Social media and physicians: the Indian scenario}

Published online on November 23, 2017. DOI:10.20529/ IJME.2017.099.

Once online, it's always online.

-Anonymous

Consent and ethics are integral to a physician's work. Patient images have been used for multiple purposes in medical practice; as an adjunct to clinical care, displayed to colleagues, students and other audiences in educational settings, and published in medical journals. But nowadays there is an increasing trend towards sharing patient pictures and videos online, on social media platforms. Though usually shared privately with friends, these photographs and videos end up in the public domain, accessible to everyone. Most often, these photographs do not even comply with the basic rules of clinical photography, especially of making the patient unrecognisable. Such behaviour on the part of a physician, some may say, is tantamount to invasion of privacy and poses a serious threat to the relationship of trust between doctor and patient. A physician should always respect his patient's privacy (1). In hospitals, patients usually feel a sense of gratitude towards the physician treating them. As a result, patients usually don't complain when their photographs are shared by doctors (2). Though the responsibility for these photographs shared online lies with the physician, patients must be made aware that with the evolution of electronic publication, once an image is published there is no efficient control over its future misuse.

There is also the issue of getting written consent from patients for the use of their photographs. None of the photos shared on social media has accompanying information regarding the patient's consent. Patients should be informed clearly about the use of their photographs, and written consent should be mandatorily received before sharing any photograph or video for any purpose including clinical publications, especially sharing on the social media. With the proliferation of published images on the internet it has become particularly important to obtain permission for all uses that will be made of patients images and videos, including worldwide distribution through various electronic media (3). The blanket consent used for the patient's treatment does not cover these factors.

We would recommend using the protocol applicable to clinical photography while using the patient's material on the media and that only after getting the patient's informed consent for the same (4). Efforts should be made to anonymise the images and photographs used so that such information does not raise ethical and legal concerns (5).

Prateek (neopatricks@gmail.com), Department of Anaesthesiology, Dr SN Medical College, Jodhpur; Himani Tak (cleotak@gmail.com), Resident, Department of Community Medicine, Dr SN Medical College, Jodhpur.

\section{References}

1. International Committee of Medical Journal Editors. Protection of patients' rights to privacy. BMJ 1995 Nov;311(7015):1272.

2. Nicholl D, Davies D. Videos, photographs, and patient consent: most patients agree to be videoed for teaching and publication purposes [letter].BMJ 1998 Nov;317(7171):1523.

3. Dysmorphology Subcommittee of the Clinical Practice Committee, American College of Medical Genetics, Cunniff C, Byrne JLB, Hudgins LM, Moeschler JB, Olney AH, Pauli RM, Seaver LH, Stevens CA, Figone C. Informed consent for medical photographs. Genet Med. 2000 NovDec;2(6):353-5.

4. Bhattacharya S. Clinical photography and our responsibilities. Indian J Plast Surg :2014 Sep-Dec;47(3):277-80.

5. Mavroforou A, Antoniou G, Giannoukas AD. Ethical and legal aspects on the use of images and photographs in medical teaching and publication. Int Angiol. 2010 Aug;29(4):376-9.

\section{Menstruation: a complex saga}

\section{DOI:10.20529/IJME.2018.005}

In their letter, Singh and Thawani (1) highlight the gender insensitivity of the government which, after declaring items such as sindoor, bindis and condoms as tax-free, opted to levy $12 \%$ tax on sanitary napkins, equating the napkin with items such as packaged dry fruits, fruit juices, cell phones and so on (2). While the new sanitary napkin tax is actually a drop from the earlier $14.5 \%$, in a regime where all taxes were reconsidered and revised, the authors' argument that sanitary napkins should have been exempted from tax is absolutely valid.

Taking off from their letter, I wish to draw attention to the fact that taxes on sanitary napkins are a symptom - of a state/ society that is both schizoid and callous: sanitary napkins are required because women have menstrual cycles and the cycles are, to evoke Simone de Beauvoir (3) part of essential female physiology; absence of menstruation could imply, among other things, an infertile female body, and infertility, which translates into the incapacity of a woman to contribute to creating the next generation. This definitely does not fit into the state's scheme of things either, and yet, when the female body shows visible physical signs of fertility, the state levies taxes on products which come in to provide some degree of comfort and ease to women. Talk of paradoxes!

The issue is, among others, one of evaluating and comprehending the female body and its processes, in this case, specifically, menstruation. Sophie Laws in Issues of Blood points out that the way a society deals with menstruation reveals much about how it perceives women (4). Let's ask, why are condoms untaxed? Simple: the state wishes to keep population growth rates and incidence rates of HIV under check. The male condom, in terms of functionality, helps contain semen - a bodily secretion - ejaculated by the male body. So does the sanitary napkin with respect to menstrual blood, a bodily secretion, but because the spilling over of this blood does not threaten the state with population boom or a pandemic, napkins are considered an item of luxury, in other words, optional.

But this is not to say that the state - as placeholder of a male panopticon - is at ease with female bodily fluids: many of 